\title{
Airway Management Options in Head Trauma with Cervical Spine Injury
}

\author{
Surjya Prasad Upadhyay* \\ Specialist Anaesthesiology, NMC Royal Hospital DIP, United Arab Emirates
}

Submission: August 01, 2018; Published: September 28, 2018

*Corresponding author: Surjya Prasad Upadhyay, Specialist anaesthesiology, NMC Royal Hospital DIP, Dubai Investment Park, Dubai, UAE, Tel: 00971-554078445; Email: run77in@yahoo.com

\section{Introduction}

Airway management is a crucial step for prevention of secondary brain injury in the management of Traumatic Brain Injury (TBI) as untreated hypoxia and hypercarbia can significantly worsen the neurological outcome. Most patients with severe TBI require urgent intubation to secure and protect the airway and to assist mechanical ventilation. Securing airway is an urgent and essential component in the management of severe Traumatic Brain Injury (TBI). Airway manipulation (laryngoscopy, intubation) may also has the potential to worsen Intracranial Pressure (ICP) by stimulating the cough and gag reflexes in addition to autonomic responses. In addition, many patients with TBI sustains have also multiple other injuries and present numerous challenges beyond intubation of trachea, outcome of which is depends on skill and experience of the operator to predict and formulate a clear plan and execute it smoothly $[1,2]$. Use of anaesthetic agents to facilitate intubation is also not without any risk, use of certain sedative / muscle relaxant may cause profound hypotension in patients with hypovolemia due to blood loss, which may aggravate further aggravate the already damage brain. The choice of sedation / muscle relaxant have to be decided against the risk of hypotension $[2,3]$.

TThere is growing evidences to support that early placement of advanced airway reduces mortality in patients with polytrauma including TBI [4-6]. Primary purpose of intubation in TBI (unless the patient is severely hypoxic) is to secure \& protect the airway and is usually can be planned with proper preoxygenation and preparation to prevent the physiological disturbances during airway manipulation. Most of these patients are intubated using Rapid Sequence Intubation (RSI) technique which involves administration of sedative agent and rapidly acting paralysing agent in quick succession to facilitate placement of endotracheal tube and is considered the standard approach for airway management in patients with trauma [7-9]. Primary purpose of RSI is to secure the airway as soon as possible with minimal risk of aspiration as all trauma patients are presumed to have full stomach. RSI is considered the standard approach for airway management in patients with trauma [7-9].

Protection and immobilization of cervical spine (C spine) is essential in all trauma patients with altered level of consciousness.
Securing airway is an urgent and essential component in the management of severe Traumatic Brain Injury (TBI). To prevent or minimise the risk of secondary spine injury during airway management, the $\mathrm{C}$ spine must be stabilized by avoiding undue movement. Assessment of airway in fundamental and based on impression of initial assessment, appropriate technique or option is chosen. As the airway management in TBI is often an urgent or emergent situation limiting its detail assessment and evaluation as time play a crucial factor [10-13]. Moreover, other co-existing issues like physiologic status, patient cooperation, application of spine immobilisation devices in addition to direct injury to face and airway also hinder the proper assessment of the airway. Even limited information may be tremendously helpful in difficult situation. Airway management plan is formulated based on initial impression, patient specific data (anatomical injury, physiological status) and information obtained during assessment of airway. Airway plan should include a stepwise approach as initial primary approach or technique as well as alternative technique if the initial technique fails $[12,13]$.

\section{Mask ventilation}

Ability to performed effective mask ventilation is often limited due to application of immobilisation devices like hard cervical collar, presence of blood or vomitus, direct trauma to face and airway and essential need to keep head and neck in neutral position to prevent any further spine injury. It is critical to assess the difficult mask ventilation in trauma patients. When mask ventilation seems difficult, early use of airway adjuncts such as oral or naso -pharyngeal airways are encouraged instead of trying excessively the trying excessively the head and neck manoeuvres to open the airway. Long acting muscle relaxant is dangerous and should never be used when encountered with difficult mask ventilation. Alternative plan or technique of airway management should be considered early such as awake intubating or surgical airway based on the facility available and expertise of the operators.

\section{Conventional intubation using Direct laryngoscopy}

Traditional teaching says all unconscious patients with TBI should presumed to have unstable cervical spine (C-spine) until 
proven otherwise. However, the true incidence of C-spine injury is relatively low approximatively $2 \%$ in general trauma which increases to $8 \%$ in patients with head and facial trauma. This create an over exaggerated concern or risk of cervical cord injury during laryngoscopy \& intubation making the normal airway into difficult one $[14,15]$. This does not imply that $C$ spine should be ignored at all, C-spine injury should always be keep in mind and be very gentle during laryngoscopy and intubation with $\mathrm{C}$ spine immobilisation device or manual in-line stabilisation of $\mathrm{C}$ spine to avoid excessive flexion, extension or rotation of neck. Use of rigid collar often makes the laryngoscopy difficult, the collar can be temporarily removed to allow for gentle laryngoscopy. Manual In-Line Stabilisation (MILS) is a technique or manoeuvre which is used by an assisted using both hands on either side of neck to keep head and neck in neutral position and to offset any movement of the $\mathrm{C}$ spine that might occur during laryngoscopy and intubation. Though the application of MILS is considered a standard of care in prevention or reduction of secondary injury to C-spine during airway management, its efficacy is still unclear, on the other hand, MILS does impair the laryngoscope view and often makes tracheal intubation difficult. Some clinicians have challenged its routine application. MILS may be useful in reducing overall excessive cervical spine movements but has limited effect at mid cervical point of injury [14-16]. The movement of spine during laryngoscopy in unstable $\mathrm{C}$ spine do not significantly exceed the physiological values of normal intact spine movement $[17,18]$ Patient with cervical spine injuries, the secondary neurological deterioration after laryngoscopy and intubation is very rare, with a reported incidence of less than $0.05 \%$ [19-21]. Gentle external laryngeal manipulation and use of bougie guided intubation are often extremely helpful in reducing the number of failed attempts [2].

\section{Indirect laryngoscopy using videoscope}

Video-laryngoscopes with hyper angulated blade (glidoscope, D blade of C mac, Mc grath mac) often provides a better view of laryngeal inlet compared to conventional laryngoscope when spine mobility is greatly restricted due to MILS or spine immobiliser [2225]. However, a good view on video laryngoscopy may not reflect as easy placement of ETT, a deliberate restricted glottic view may be more desirable to facilitate intubation than having a great view with failed attempts [26,27]. So far, no device or approach has consistently yielded superiority over others. Suppan et al. [25] conducted a meta-analysis of direct laryngoscopy and 6 others newer video laryngoscopies in $\mathrm{C}$ spine immobilised patients requiring intubation. Conventional direct laryngoscopy has higher failure rate compared to other newer alternative devices (video laryngoscopes) for intubation [25]. The Air tray was associated with a significant reduction of the risk of intubation failure at the first attempt [28]. However, the available literature was too weak to make a statistically significant difference. It may be the experience and right skill of the practitioner on a particular device with which he or she is more confidence rather than a "one device that fit all" in unstable $C$ spine injury $[29,30]$. A balance approach between minimising movement of $\mathrm{C}$ spine and quick and successful placement of ETT on first attempt should be utilised in patients with suspected C-spine injury [30]. If the Cervical spine has survived the insult during the initial trauma, as well as repositioning during extraction and immobilisation, the risk of spinal cord injury during airway management in a controlled manner is extremely rare [15,31].

\section{Awake intubation}

Successful awake intubation requires proper patient selection through identifying factors that might be hindrance to conventional airway management during RSI. Patients with isolated C -spine injury, or burn or trauma to airway, awake intubation may be appropriate choice to mitigate the difficulty of securing the airway or avoid the dynamic anatomical or physiological changes. Patient cooperation and maintenance of spontaneous respiration is crucial in awake intubation and is delayed sequence intubation requiring time approach for preparing the airway with adequate topical local anaesthetics. Awake intubation is not a device specific, especially in trauma; it can be performed with either conventional direct laryngoscopy, video laryngoscopy or fibreoptic guided intubation [32,33]. Sedative medication with least interference with respiration is desirable, but is not always mandetory, inappropriate use of sedative to counteract the inadequate topicalization are often associated with higher failure rate in awake intubation. Fibreoptic guided awake intubating is excellent as it allows for assessment and documentation of neurological exam before and after the intubation, but it require a cooperative patient and not ideal in emergency situation specially in trauma where presence of blood, secretion limits its usefulness. Moreover, it requires considerable expertise to use in emergency trauma cases.

\section{Supraglottic airway}

Newer generation supraglottic airways (I gel, intubating laryngeal mask airway) which can be used as conduit for fibreoptic guided endotracheal intubation can be a great rescue device both in difficult mask ventilation or difficult intubation. These devices can be quickly and easily inserted without much manipulation of airway and they function best in spontaneously breathing patients. However, these devices might exert considerable pressure that theoretically can displace the injured $\mathrm{C}$ spine. The safety of supraglottic airway in TBI is doubtful and endotracheal tube still hold the upper hand as primary device for airway management. Supraglottic airway should only be consider as rescue device when ETT.

\section{Surgical airway}

Historically surgical airway or cricothyrotomy was once strongly advocated as first line technique over direct laryngoscopy to minimize $\mathrm{C}$ spine injury, but it was not well studied or practised. With advancement in airway gadget, its role as primary first line airway management technique is questionable except in patients with direct penetrating trauma to airway. It is always a rescue 
technique when other conventional method failed to secure the airway.

Practical pearls while handling airway management in unstable cervical spine injury

a. Airway management should not be delayed by imaging studies to rule out $\mathrm{C}$ spine injury.

b. First attempt is always the best attempt.

c. Practitioner should optimally use the intubation device for which he or she is more familiar and is most experienced with.

d. Always prepared and keep ready intubation aids like bougie and another alternative device. Call for help early.

e. Rigid cervical collar should be opened or temporarily removed and replaced by MILS.

f. While using hyper angulated video laryngoscopy, a deliberate restricted laryngeal view facilitate placement of ETT better than a greater improved laryngeal view.

g. Awake intubation may be safe in selected patients.

h. Supraglottic airway- can be used as both rescue device in difficult to intubate as well as conduit for fibreoptic guided intubation.

i. Surgical airway is always a salvageable technique when non-surgical technique fails and often can be considered as first line technique in direct trauma to airway.

\section{References}

1. Kovacs G, Sowers N (2018) Airway Management in Trauma. Emerg Med Clin N Am 36 (2018): 61-84.

2. Kramer N, Lebowitz D, Walsh M, Ganti L (2018) Rapid Sequence Intubation in Traumatic Brain injured Adults. Cureus 10(4): e2530.

3. Roberts DJ, Hall RI, Kramer AH, Robertson HL, Gallagher CN, et al. (2011) Sedation for critically ill adults with severe traumatic brain injury: a systematic review of randomized controlled trials. Crit Care Med 39: 2743-2751.

4. Miraflor E, Chuang K, Miranda MA, Dryden W, Yeung L, et al. (2011) Timing is everything: delayed intubation is associated with increased mortality in initially stable trauma patients. J Surg Res 170(2): 286290.

5. Mayglothling J, Duane TM, Gibbs M, McCunn M, Legome E, et al. (2012) Emergency tracheal intubation immediately following traumatic injury: An Eastern Association for the Surgery of Trauma practice management guideline. J Trauma Acute Care Surg 73(5): S333-S340.

6. Asehnoune K, Roquilly A, Cinotti R (2018) Respiratory Management in Patients with Severe Brain Injury. Critical Care 2018 22: 76.

7. Salem MR, Clark Wronski J, Khorasani A, Arjang, Crystal, George J et al. (2013) Which is the original and which is the modified rapid sequence induction and intubation? Let history be the judge! Anesth Analg 116(1): 264-265.

8. Tobias JD (2014) Rapid sequence intubation: what does it mean? Does it really matter? Saudi J Anaesth 8(2): 153-154.
9. Ehrenfeld JM, Cassedy EA, Forbes VE, Mercaldo ND, Sandberg WS et al. (2012) Modified rapid sequence induction and intubation: a survey of United States current practice. Anesth Analg 115(1): 95-101.

10. Levitan RM, Everett WW, Ochroch EA (2004) Limitations of difficult airway prediction in patients intubated in the emergency department. Ann Emerg Med 44(4): 307-313.

11. Bair AE, Caravelli R, Tyler K, Laurin EG (2010) Feasibility of the preoperative Mallampati airway assessment in emergency department patients. J Emerg Med 38(5): 677-680.

12. Diedrich DA, Rose PS, Brown DR (2013) Airway management in Cervical spine injury. Curr Anesthesiol Rep 3(3): 197-204.

13. Austin N, Krishnamoorthy V, Dagal A (2014) Airway management in cervical spine injury. International Journal of Critical Illness and Injury Science 4(1): 50-56

14. Mulligan RP, Friedman JA, Mahabir RC (2010) A nationwide review of the associations among cervical spine injuries, head injuries, and facial fractures. J Trauma 68(3): 587-592.

15. Manoach S, Paladino L (2007) Manual in-line stabilization for acute airway management of suspected cervical spine injury: historical review and current questions. Ann Emerg Med 50(3): 236-245.

16. Thiboutot F, Nicole PC, Trepanier CA, Turgeon AF, Lessard MR (2009) Effect of manual in-line stabilization of the cervical spine in adults on the rate of difficult orotracheal intubation by direct laryngoscopy: a randomized controlled trial. Can J Anaesth 56(6): 412-418.

17. Hindman BJ, Fontes RB, From RP, Traynelis VC, Todd MM et al. (2016) Intubation biomechanics: laryngoscope force and cervical spine motion during intubation in cadavers-effect of severe distractiveflexion injury on C3-4 motion. J Neurosurg Spine 25(5): 545-555.

18. Hindman BJ, From RP, Fontes RB, Traynelis VC, Todd MM, et al. (2015) Intubation biomechanics: laryngoscope force and cervical spine motion during intubation in cadavers-cadavers versus patients, the effect of repeated intubations, and the effect of type II odontoid fracture on C1-C2 motion. Anesthesiology 123(5): 1042-1058.

19. Durga P, Sahu BP (2014) Neurological deterioration during intubation in cervical spine disorders. Indian J Anaesth 58(6): 684-692.

20. Crosby ET (2006) Airway management in adults after cervical spine trauma. Anesthesiology 104(6): 1293-1318.

21. Farmer J, Vaccaro A, Albert TJ, Malone S, Balderston RA, et al. (1998) Neurologic deterioration after cervical spinal cord injury. J Spinal Disord 11(3): 192-196

22. Kovacs G, Law JA (2016) Lights camera action: redirecting video laryngoscopy. EMCrit.

23. Bathory I, Frascarolo P, Kern C, Schoettker P (2009) Evaluation of the Glide Scope for tracheal intubation in patients with cervical spine immobilisation by a semi-rigid collar. Anaesthesia 64(12): 1337-1341.

24. Michailidou M, O Keeffe T, Mosier JM, Friese RS, Joseph B, et al. (2015) A comparison of video laryngoscopy to direct laryngoscopy for the emergency intubation of trauma patients. World J Surg 39(3): 782-788.

25. Suppan L, Tramer MR, Niquille M, Grosgurin O, Marti C et al. (2016) Alternative intubation techniques vs Macintosh laryngoscopy in patients with cervical spine immobilization: systematic review and meta-analysis of randomized controlled trials. Br J Anaesth 116(1): 27-36.

26. Gu Y, Robert J, Kovacs G, Milne AD, Morris I, et al. (2016) A deliberately restricted laryngeal view with the Glide Scope video laryngoscope is associated with faster and easier tracheal intubation when compared with a full glottic view: a randomized clinical trial. Can J Anaesth 63(8): 928-937. 
27. Crosby ET (2007) Considerations for airway management for cervical spine surgery in adults. Anesthesiol Clin 25(3): 511-533.

28. Duggan LV, Griesdale DE (2015) Secondary cervical spine injury during airway management: beyond a "one-size-fits-all" approach Anaesthesia 70(7): 769-773.

29. Higgs A, Cook TM, McGrath BA (2016) Airway management in the critically ill: the same, but different. Br J Anaesth.

30. Lapinsky SE (2015) Endotracheal intubation in the ICU. Crit Care 19(1): 258.

31. Cook TM, Woodall N, Harper J, Benger J; Fourth National Audit Project (2011) Major complications of airway management in the UK: results of the Fourth National Audit Project of the Royal College of Anaesthetists and the Difficult Airway Society. Part 2: intensive care and emergency departments. Br J Anaesth 106(5): 632-642.

32. Mayglothling J, Duane TM, Gibbs M, McCunn M, Legome E, et al. (2012) Emergency tracheal intubation immediately following traumatic injury: An Eastern Association for the Surgery of Trauma practice management guideline. J Trauma Acute Care Surg 73: S333-S340.

33. Kihara S, Watanabe S, Brimacombe J, Taguchi N, Yaguchi Y, et al. (2000) Segmental cervical spine movement with the intubating laryngeal mask during manual in-line stabilization in patients with cervical pathology undergoing cervical spine surgery. Anesth Analg 91(1): 195-200.

\section{Your next submission with Juniper Publishers will reach you the below assets}

- Quality Editorial service

- Swift Peer Review

- Reprints availability

- E-prints Service

- Manuscript Podcast for convenient understanding

- Global attainment for your research

- Manuscript accessibility in different formats

( Pdf, E-pub, Full Text, Audio)

- Unceasing customer service

Track the below URL for one-step submission

https://juniperpublishers.com/online-submission.php 